PARENT-HEALTHCARE PROVIDER RELATIONSHIPS AFTER PICU DEATH

\title{
Gradually Disengaging: Parent-Healthcare Provider Relationships After a Child's Death in the Pediatric Intensive Care Unit
}

\author{
Ashleigh E. Butler, RN, PhD, BNurs, MNurs \\ Research Associate, The Louis Dundas Centre for Children's Palliative Care, \\ University College London/Great Ormond Street Institute of Child Health \\ Mailing address: PO Box 2742, \\ Rowville, Victoria \\ Australia 3178 \\ Email:-Ashleigh.Butler@ucl.ac.uk \\ Helen Hall, PhD, RN, RM, ND, GCHE \\ Head of Campus, School of Nursing and Midwifery \\ Monash University \\ Peninsula Campus, McMahons Road \\ Frankston, Victoria \\ Australia, 3199 \\ Phone: +6 399044120 \\ Email: Helen.Hall@monash.edu \\ Beverley Copnell, PhD, RN, BAppSci (Advanced Nursing), GCHE. \\ Associate Professor of Clinical Practice Nursing and Director of the Northern Clinical School \\ School of Nursing and Midwifery \\ La Trobe University \\ 185 Cooper St. \\ Epping, Victoria \\ Australia, 3076. \\ Phone: +6138468 0701 \\ Email: b.copnell@latrobe.edu.au
}

Keywords: parent-healthcare provider relationship, pediatric intensive care, death, grounded theory 


\section{Biographical Paragraphs}

Ashleigh E. Butler, RN, PhD, BNurs, MNurs is a pediatric and adult intensive care nurse at Monash Health in Victoria, Australia, currently working as a research associate at the Louis Dundas Centre for Children's Palliative Care at UCL Great Ormond Street in London. She recently completed her doctoral research at Monash University where she examined parentstaff relationships when a child dies in the PICU. Her research interests include end-of-life care and bereavement follow-up for children and their families in the PICU, family-centred care, pediatric critical care, and practical and ethical issues associated with researching children and their families at the end of life. Recent publications include:

Butler, A., Copnell, B., \& Hall, H. (2017). The impact of the social and physical environments on parent-healthcare provider relationships when a child dies in PICU: Findings from a grounded theory study. Intensive \& Critical Care Nursing. Advance online publication. https://doi.org/10.1016/j.iccn.2017.12.008

Butler, A. E., Hall, H., \& Copnell, B. (2018). The changing nature of relationships between parents and healthcare providers when a child dies in the paediatric intensive care unit. Journal of Advanced Nursing, 74, 89-99. https://doi.org/10.1111/jan.13401

Butler, A. E., Hall, H., \& Copnell, B. (2017). Ethical and practical realities of using letters for recruitment in bereavement research. Research in Nursing \& Health, 40, 372-377. https://doi.org/10.1002/nur.21800

Helen Hall, RN, PhD, BNurs, MNurs is a senior lecturer and Head of Campus (Peninsula) for Monash University Nursing and Midwifery in Australia. Her research interests include infant and children's health, midwifery education, and integrative medicine. Recent publications include:

Butler, A., Copnell, B., \& Hall, H. (in press). The impact of the social and physical environments on parent-healthcare provider relationships when a child dies in PICU: Findings from a grounded theory study. Intensive \& Critical Care Nursing. https://doi.org/10.1016/j.iccn.2017.12.008

Bailey, C., Newton, J., \& Hall, H. (2017). Telephone triage and midwifery: A scoping review. Women and Birth. Advance online publication. https://doi.org/10.1016/j.wombi.2017.12.002

Hall, H., Leach, M., Brosnan, C., \& Collins, M. (2017). Nurses' attitudes towards complementary therapies: A systematic review and meta-synthesis. International Journal of Nursing Studies, 69, 47-66. https://doi.org/10.1016/j.ijnurstu.2017.01.008

Beverley Copnell, PhD, RN, BAppSci (Advanced Nursing),GCHE is an associate professor of Clinical Practice Nursing and Director of the Northern Clinical School at La Trobe University in Melbourne Australia. Her research interests include end-of-life care for 
infants and children in acute care settings, family centred care, paediatric and neonatal critical care, nursing education, and evidence-based practice. Recent publications include:

Butler, A. E., Hall, H., \& Copnell, B. (2018). The changing nature of relationships between parents and healthcare providers when a child dies in the paediatric intensive care unit.

Journal of Advanced Nursing, 74, 89-99. https://doi.org/10.1111/jan.13401

Alabdulaziz, H., Moss, C., \& Copnell, B. (2017). Paediatric nurses' perceptions and practices of family-centred care in Saudi hospitals: A mixed methods study. International Journal of Nursing Studies, 69, 66-77. https://doi.org/10.1016/j.ijnurstu.2017.01.011

Zhong, Y., McKenna, L., \& Copnell, B. (2017). What are Chinese nurses' experiences whilst working overseas? A narrative scoping review. International Journal of Nursing Studies, 74, 101-111. https://doi.org/10.1016/j.ijnurstu.2017.06.009 
PARENT-HEALTHCARE PROVIDER RELATIONSHIPS AFTER PICU DEATH

\begin{abstract}
When a child dies in the intensive care unit, many bereaved parents want relationships with their child's healthcare staff to continue in the form of follow up care. However, the nature of these relationships and how they change across the parents' bereavement journey is currently unknown. This paper explores early and ongoing relationships between parents and healthcare staff when a child dies in intensive care. Constructivist grounded theory methods were used to recruit 26 bereaved parents from four Australian pediatric intensive care units into the study. Data were collected via audio-recorded, semi-structured interviews, and analysed using the constant comparative methods and theoretical memoing. Findings show that these relationships focus on Gradually disengaging, commonly moving through three phases after the child dies: Saying goodbye, Going home, and Seeking supports. These findings provide guidance to healthcare staff on what families need as they leave the intensive care unit and move through bereavement.
\end{abstract}

Funding: This work was supported by the Australian College of Critical Care Nurses [Novice Researcher Grant]; and the Australian College of Children and Young People's Nurses [Sister Mary Dorothea Sheehan Scholarship]. A. Butler was supported by an Australian Government Research Training Program Scholarship.

Address all correspondence to: Ashleigh E. Butler, PO Box 2742, Rowville, Victoria, Australia, 3178. Email: Ashleigh.butler@ucl.ac.uk 
PARENT-HEALTHCARE PROVIDER RELATIONSHIPS AFTER PICU DEATH

The pediatric intensive care unit (PICU) provides speciality lifesaving care to critically ill and injured infants and children. This care is delivered by highly trained medical, nursing and allied health staff, who maintain a constant vigil by the sick child's bedspace. Such constant presence often fosters a close connection between staff and the child's parents, who usually want to remain by their child's side as much as possible (Ames, Rennick, \& Baillargeon, 2011; Hall, 2005; Lamiani, Giannini, Fossati, Prandi, \& Vegni, 2013; McGraw et al., 2012; Meyer, Ritholz, Burns, \& Truog, 2006). Across their time in PICU, many parents come to develop relationships with the healthcare staff, relying on them for everything from involvement in their child's care, to distractions from their situation, and psychological support (Brooten et al., 2013; Meert, Briller, Schim, Thurston, \& Kabel, 2009; Michelson, Patel, Harber-Barker, Emanuel, \& Frader, 2013; Yorke, 2011). In reality, parents often develop such close attachments to healthcare staff that they come to regard them as family, particularly when a child is hospitalized for a prolonged period of time (Brooten et al., 2013; Meert et al., 2009; Meyer, Burns, Griffith, \& Truog, 2002). For the parents of the 2-10\% of children who will die in intensive care units worldwide each year (Australian and New Zealand intensive care registry (ANZPICR),2016; Devictor, Latour, \& EURYDICE II study group, 2011; Kipper et al., 2005; Sands, Manning, Vyas, \& Rashid, 2009 (Burns, Sellers, Meyer, Lewis-Newby, \& Truog, 2014; PICANet, 2017), these relationships become even more important.

Many studies with bereaved parents have identified the need for support and supportive relationships from healthcare providers as the child is dying (Meert et al., 2008, 2009; Meyer et al., 2006; Michelson et al., 2013). Indeed, 'family supporter' has been identified as one of the key roles for healthcare providers in the PICU at this time (Michelson et al., 2013). However, the actual meaning of this concept of support for parents when their child is dying in the PICU is less clear. Vague descriptions of bereaved parents' desire for 
PARENT-HEALTHCARE PROVIDER RELATIONSHIPS AFTER PICU DEATH

'support' are common in the literature, often without any specific discussion of what parents define as 'supportive' behaviours. Very few studies offer any suggestions on bereaved parents' perceptions of support from staff when their child is actively dying, with those that do typically including either showing kindness and empathy (Meyer et al., 2006), providing information (Meert et al., 2008; Michelson et al., 2013), or assisting parents with paperwork, funeral plans, or participation in care (Meert et al., 2009).

Support, in the form of ongoing relationships with healthcare staff, is also frequently discussed by bereaved parents (Butler, Hall, Willetts, \& Copnell, 2015; Meert et al., 2009; Meert, Thurston, \& Briller, 2005; Yorke, 2011). The nature of these parent-healthcare provider relationships after death, what parents need from these relationships, what support means for them, and whether these support needs change across their bereavement journey, remain largely unclear. Prior studies have highlighted the importance and value of letters, phone calls, and funeral attendance from staff (Meert et al., 2009). However, ongoing recommendations for bereavement follow up and support by bereaved parents suggest these elements are not always adequately provided, or do not completely meet their need for support.

At present, there is much about the parent-healthcare provider relationship around the time a child is dying in the PICU and during early bereavement that remains unknown. Given that the interactions parents have with staff can either be a source of comfort or distress in the months and years after their child's death (Meert et al., 2009), it is important to develop a deeper understanding of what a supportive relationship with healthcare providers looks like for them. In order to provide some insight into these unknowns, we draw from a larger grounded theory study on parental experiences of the death of a child in the PICU and the interactions they have with healthcare staff during and after this time. A theory, termed Transitional togetherness, was developed in the larger study (Butler, Hall, \& Copnell, 
PARENT-HEALTHCARE PROVIDER RELATIONSHIPS AFTER PICU DEATH

2018a). Transitional togetherness described the development of and changes to parenthealthcare provider relationships across a critically ill and dying child's admission to and death in the PICU. Three key phases to this relationship were identified. Welcoming expertise describes the initial formation of the parent-healthcare provider relationship during the child's admission to PICU, focusing primarily on the parents' recognition of the healthcare staff as 'experts' and their desire to step back from many aspects of their parental role in order to prioritize their child's survival. The second phase, Becoming a team, describes the parents desire to reconstruct a role for themselves in the PICU and work together with healthcare staff to care for their child. These first two phases have been briefly described in the context of the broader theory (Butler, Hall, \& Copnell, 2018a), and have been explored in detail elsewhere (Butler, Copnell, \& Hall, 2017; Butler, Copnell, \& Hall, 2018; Butler, Hall, \& Copnell, 2018b). Here, we present a detailed discussion of the final phase of the relationship, Gradually disengaging, and introduce the parents' support needs across three key time periods: saying goodbye, going home, and during ongoing bereavement.

\section{Methods}

\section{Methodology}

We followed the constructivist grounded theory methodology, as outlined by Charmaz (2014), to undertake this study. The grounded theory methodology focuses on the experiences, behaviours, and interactions of people within their social context (Birks \& Mills, 2011; Charmaz, 2014). It aims to develop a theory to explain these social processes, which arises directly from the data itself. Within grounded theory, constructivism assumes the existence of multiple realities influenced by socio-cultural background, experience, and context (Charmaz, 2014). Data and meaning are co-constructed by both the participant and the researcher, based on shared understandings of these realities. The researcher is not viewed 
PARENT-HEALTHCARE PROVIDER RELATIONSHIPS AFTER PICU DEATH

as objective, but rather involved in creating and shaping the data with their participants

(Charmaz, 2014). As such, the developed theory represents one interpretation of the participants' realities out of many that may have been constructed. For these reasons, constructivist grounded theory allowed us to explore both the experiences of bereaved parents when their child dies in the PICU and the changing nature of their relationships with healthcare providers, making it the ideal methodology to answer the research question.

\section{Participants}

Consistent with grounded theory, purposive and theoretical sampling techniques were used to recruit participants into the study (Charmaz, 2014). We used a combination of social workers, mailed letters, and advertisements at support groups to invite bereaved parents into the study 6-48 months after their child had died. A discussion of the ethical and practical issues encountered during recruitment is published elsewhere (Butler, Hall, \& Copnell, 2017). Twenty-six parents (18 mothers and 8 fathers) from 4 Australian PICUs participated in the study, representing 18 deceased children. We were unable to collect data on the overall number of eligible parents, or the number of parents who declined participation when approached via social workers or opt-in letters. Characteristics of participant families and their follow up experiences are described in Table 1. Hospital 1 provided no formal follow up service. Hospital 2 provided a variable length follow up service, with phone calls from social workers. Hospital 3 offered a 12 month follow up program run by the social work department. Hospital 4 offered no formal personal follow up, but held intermittent (approximately 6 monthly) memorial services for all parents of deceased children.

$$
\text { [insert Table } 1 \text { about here] }
$$

\section{Data Collection}

Semi-structured, audio recorded interviews were utilized for data collection, as they allowed flexibility to explore issues of importance to both participants and the research team. 
PARENT-HEALTHCARE PROVIDER RELATIONSHIPS AFTER PICU DEATH

Interviews lasted between 90-150 minutes, and were conducted at a time and location of the participants' choice. The majority of parents opted to be interviewed in their own homes, though a small number preferred phone interviews. Early interview questions took parents through their PICU admission, journey, and their child's death, with developing themes and concepts providing direction for later questions, in line with the principles of theoretical sampling (Charmaz, 2014). For example, when coding and memoing indicated that continuity of medical or nursing carer was important to families during removal of life support and bereavement follow up, we began asking what it meant to them when familiar staff were or were not involved in these processes. We also explored whether parents felt they would have engaged more or less with any follow-up services offered to them had the involved staff members been different, in order to explore links between continuity of carer, perceptions of support, and follow-up care provision. We also recorded field notes of conversations held after the recorder was turned off, with permission. Each interview was undertaken by the first author, a PICU nurse with no prior relationship to any participant.

\section{Data Analysis}

Data analysis began immediately after the first interview and continued in a cyclic process of collection and analysis until saturation of the theory and core categories was achieved. Saturation was determined to have occurred when no new concepts, properties, or relationships were identified within and between the categories or the three main phases, and when the overall theory was robust enough to account for all variations noted in the data. Transcribed data were entered into NVivo 10 for analysis. Initially, line by line open coding of each interview transcript was undertaken by the first author, in collaboration with the research team, following the processes outlined by Charmaz (2014). Codes were developed from the data, based on meaningful processes, phrases, actions, behaviours, and ideas. 
PARENT-HEALTHCARE PROVIDER RELATIONSHIPS AFTER PICU DEATH

Constant comparison was utilized to compare codes, events and transcripts and to develop concepts and categories. Focused coding was employed, with further data collection and analysis focusing on exploring relationships between and within these categories, until theory was developed from the data. Examples of some of the codes included in each of the subcategories discussed in this paper are provided in Table 2. At each stage, developing concepts and categories were checked and explored in a variety of ways using theoretical sampling. For example, data analysis identified that many parents in the early interviews felt abandoned by hospital staff because of a lack of ongoing contact after their child's death. In order to explore this concept, new data collection sites (both with and without formal bereavement follow up programs) were added to the study, which facilitated a deeper understanding of the relationships between hospital-based follow up and parental perceptions of support during bereavement. In addition, theoretical sampling also focused on seeking out families with certain characteristics (such as the child's age, length of stay, or type of illness) as required to explore categories, and adding or adapting interview questions to explore developing concepts. The data analysis process was continually supported by theoretical memos, which provided a space for conceptualization of the data and identification of gaps within the developing theory. Memos also enabled the research team to reflect upon their own experiences as PICU nurses caring for dying children, and identify possible biases, assumptions, and worldviews that may have influenced both the data collection and analysis processes.

[insert Table 2 about here]

\section{Ethics}

Approval for this study was obtained from all relevant human research review committees prior to commencement. All study participants provided written informed consent, with verbal consent reaffirmed throughout the interview process as needed. Given 
PARENT-HEALTHCARE PROVIDER RELATIONSHIPS AFTER PICU DEATH

the highly emotional nature of the interviews, the interviewer (A.B.) undertook a bereavement counselling course prior to commencing data collection. This was not undertaken with the intention to provide counselling to participants, but rather to ensure an understanding of normal grief symptoms and facilitate identification of participants who may have need for referral to social workers involved with the study. In addition, all participants were followed up within one week of their interview, to ensure their welfare. Pseudonyms have been used for all participants and their children.

This study is reported according to the COnsolidated criteria for REporting Qualitative research (COREQ) checklist (Tong, Sainsbury, \& Craig, 2007). Consistent with grounded theory, we developed a theory directly from our data to explain the relationships between parents and healthcare providers during and after the death of a child in the PICU. The theory, Transitional togetherness, consists of three main stages: Welcoming expertise, Becoming a team, and Gradually disengaging (Butler et al., 2018a). The final stage is presented here.

\section{Findings}

Gradually disengaging describes the nature of the relationship between parents and healthcare providers during and after the death of a child in the PICU, specifically focusing on the parents' need for varying forms and levels of support. Prior to the child's death, the relationship typically focuses on both the child's need for specialized medical care and on the parents' need to reconstruct their parental role and work with the healthcare providers (Butler et al., 2018a). However, as the child's death becomes imminent, parents relinquish the need for specialized interventional care provided by the PICU. Instead of focusing solely around the child's needs, the parents' own needs, particularly for support, also become a priority. The parent-healthcare provider relationship adapts in order to fulfil the changing needs of 
PARENT-HEALTHCARE PROVIDER RELATIONSHIPS AFTER PICU DEATH

parents, as they move through their bereavement journey. Gradually disengaging typically begins during or immediately before the child's death, and consists of three main phases: Saying goodbye, Going home, and Seeking supports.

Saying goodbye describes the first phase of the relationship between parents and healthcare providers (predominantly nurses and social workers), occurring close to the time of a child's death in PICU. Parents' prior understandings of the hospital and PICU system and their place within it became inadequate. Commonly, parents did not know how to say goodbye to their child. The parent-healthcare provider relationship adapted to focus on the parents' need for support through the process of saying goodbye. Healthcare providers adopted a dominant role, guiding the parents through the process of farewelling their child. The shift in the relationship focused on the support needs of the parents to enable them to care for their child's body, an activity which many felt they would not be able to undertake on their own. Piper (hospital 2), the mother of a teenager, highlighted the importance of this support, commenting that activities like bathing her deceased child "became a little bit more than I expected for me. Um...I was right washing the top part but then when we rolled and I realised all the blood... I thought, 'I can't do that', so I just held him and looked away." However, with the support of the staff, Piper felt able to provide the level of post-mortem care to her deceased child that she desired. At times, healthcare providers took on a surrogate role under the direction of the parents, supplementing or performing tasks that the parent wanted done but felt unable to perform themselves. This was evidenced by Alice (hospital 3), the mother of a toddler, who commented: "I asked them to dress him. In something special. I couldn't bring myself to do that. Um...so I asked them to put on nice clothes. And they did it for me."

In addition, for many parents, a supportive relationship with healthcare providers meant they were able to create mementos of their child. It was commonly the healthcare 
PARENT-HEALTHCARE PROVIDER RELATIONSHIPS AFTER PICU DEATH

providers who suggested taking photos or making hand or foot prints, because parents, unfamiliar with how to say goodbye often had "no idea that [those] services even exist" (Jasmine, hospital 4). Staff also supported parents through the physical process of creating mementos, with Edward (hospital 2) commenting that staff "helped do that [make hand and footprints], I think. [The social worker] was there showing us how to do it”. This assistance was particularly important when siblings were involved, with parents appreciating when social workers "got the kids involved and made hand prints out of glitter (Abigail, hospital 2).

For parents, supportive relationships with healthcare providers meant they could create a sense of family intimacy when their child was dying. Healthcare providers respected and, where possible, facilitated parents' need for a private space, and ensured they "got to spend a fair bit of time with her afterwards" (Connor, hospital 4). Provision of such support ensured parents felt cared for and about, particularly if healthcare providers they already knew were present during their child's death. If these elements were missing, some parents felt their child's death "was a very impersonal process" (Imogen, hospital 4). They felt rushed in having to say goodbye, or felt that care was protocol driven rather than based on their personal needs. This was particularly the case if mementos were created because it was common practice, rather than because parents wanted them. For example, Jessica (hospital 4) commented that staff "cut a little bit of her hair and put it in a little baggie" as part of normal practice when someone dies, but that such actions upset her because "we most certainly didn't want a lock of her hair".

The context of the family's experiences also shaped their perceptions. For example, many of these elements of support were enhanced by the presence of staff members, such as nurses, doctors, or social workers, already known to the family. Continuity of carer exerted significant influence over how supported parents felt to say goodbye to their child. This was clearly highlighted by Imogen (hospital 2), who remarked that she felt her child's death was 
PARENT-HEALTHCARE PROVIDER RELATIONSHIPS AFTER PICU DEATH

very impersonal because there were "a whole new set of people who were around me through that death, through the decision to turn off the life support and drive home from the hospital." The desire for continuity of carer during death often extended to the point of asking "for the original physician that we had that first night to come in and take her off the ventilator" (Vicki, hospital 4). Most participants preferred that these familiar staff conducted end-of-life care discussions, withdrew therapy, and assisted with post-mortem care, because of the trust and close rapport they had already developed with them.

Once parents had said goodbye to their child, they began the process of Going home. The relationship between parents and healthcare providers again adapted to the parents' changing needs, focusing on supporting them to leave the hospital without their child. Parents often did not know the procedures associated with leaving the hospital. Feelings of "well, what do I do now?" (Isabelle, hospital 1) were commonplace, with parents needing the healthcare providers (primarily nurses) to act as a support person and guide them through the process. As they attempted to go home, parents' support needs were varied. Some parents wanted to have "someone there to talk to from the hospital, even if it was just for 15 minutes to half an hour" (Charlie, hospital 4), with others wanting assistance to pack up their child's belongings. Many parents also expressed a desire for the hospital to "offer some service like, 'would you like us to drive your car home for you?'” (Lucy, hospital 1), commenting that they "don't even know if parents should be driving their car when their child's just died" (Imogen, hospital 2). At the very least, parents needed someone to walk them out of the PICU and the hospital, making sure they were not alone as they left.

Despite differing support needs, almost all parents described a desire for the continued presence of healthcare providers as they attempted to go home. This was described as a "transitional time" or "a warm down" (Zara, hospital 1), with the previously ubiquitous presence and support of the healthcare provider slowly withdrawn. However, when this 
PARENT-HEALTHCARE PROVIDER RELATIONSHIPS AFTER PICU DEATH

ongoing supportive relationship was missing, parents described feeling "a void between when she passed away to going home" (Charlie, hospital 4). This feeling was highlighted by Zara, who said: "You need to warm down. We've just sprinted this full...we've sprinted a marathon, but there's no...it's just, okay stop now. There's no walk it off or anything like that". The sudden cessation of the intensive relationships with healthcare providers left many parents feeling "like everyone just left you" (Ryan, hospital 1). The perception that staff "kind of just moved on" (Lucy, hospital 1) to the next patient or task was strong. According to Layla, the staff are “done with you. It's like they've done their job, [so] what do we need to do for you now? Nothing." This sudden removal of the parent-healthcare provider relationship left parents feeling as though staff did not care about them or their child. As commented by Daniel (hospital 1), "Once Olivia had passed, we almost felt...abandoned."

Finally, Seeking supports described the parents' need for longer term, ongoing support, typically with someone with whom they had already developed a relationship in the PICU. For most parents, their continued relationship with healthcare providers centred around this need, with support gradually withdrawn over a number of months. Very early in bereavement, parents wanted this relationship to remain close, wanting "a phone call a few days later" (Emma, hospital 1) from healthcare providers. The relationship needed to be gradually tapered off over time, with parents wanting someone to "be in contact in a few days or a week, then lessen it out" (Layla, hospital 4), and contact continuing for the first year after death. Erin (hospital 4) noted that "the hardest for me was the first year, but especially the anniversary of the first year", and really wanted "any follow-up of or acknowledgement of that time". However, it is important to note that not all parents wanted or needed an ongoing relationship, though they recognized the importance of having it offered so "it's there if you need it" (Joshua, hospital 1). For these parents, though, the offer of support should have been "an ongoing thing.....it's got to be an open invitation" (Joshua, hospital 1), because they 
PARENT-HEALTHCARE PROVIDER RELATIONSHIPS AFTER PICU DEATH

often found that "over a year on... now I feel like is when I could use the support" (Jasmine, hospital 4).

For those who wanted it, ongoing support and connection to healthcare staff was demonstrated in a variety of ways. Primarily, parents needed and appreciated offers of psychosocial support from nurses, doctors, and social workers. They appreciated staff who "made it very clear when I left that if I needed to talk to her, just let her know" (Alice, hospital 3), and commented favourably when staff "made a phone call after a week just to check in and see how you're going" (Imogen, hospital 2). If such follow up could not be provided by the hospital itself, parents appreciated it when staff referred them to bereavement support or counselling services for ongoing psychological support. In addition, maintaining a supportive relationship with healthcare staff, particularly doctors, allowed clarification of the medical facts surrounding the child's death, which helped parents like Jessica (hospital 4) work through "any kind of last minute questions we had or feelings that got brought up by the experience." More concrete demonstrations of support were also highly valued, with parents appreciating when "someone came along from the hospital and was there at the funeral" (Charlie, hospital 4) or when staff sent cards and letters. Demonstrating a continued supportive relationship in these ways allowed parents "to feel that somebody really cares" (Imogen, hospital 2) about both them and their child. A sense of ongoing support was particularly noted if ongoing contact occurred with someone "we had already developed rapport with, and who knew the journey" (Erin, hospital 4). Nate (hospital 4) commented that "you've been through so much with them, [so] just to have that continuation... that would be nice."

Many parents, however, found that "once you left the hospital, that was it. There wasn't no follow up" (Layla, hospital 4). This was particularly true for parents from hospitals 1 and 4, though some parents from hospitals 3 and 4 also shared similar comments. Parents 
PARENT-HEALTHCARE PROVIDER RELATIONSHIPS AFTER PICU DEATH

often commented that the hospital "failed a little bit in their aftercare service" (Alice, hospital 3). For most parents, this lack of an ongoing parent-healthcare provider relationship left them feeling “like, well, the hospital's forgotten. You know, they've cut all ties and they've forgotten and they've moved on" (Zara, hospital 1). According to Layla (hospital 4), this lack of support “didn’t feel right after Lucas passed. It was like they just didn’t care”. She felt that the hospital had "forgotten you even had a child", with the lack of acknowledgement making her feel as though “he wasn't seen as a person or a baby anymore. He was just a statistic to them." As a result, 18 out of the 28 parents who took part in the study also attempted to seek out their own support, turning to their local doctor, family and friends, or approaching local bereavement support services for help. However, most parents only reached out once or twice, as noted by Nate (hospital 4): "we tried to get in contact with SIDS [SIDS and KIDS bereavement support service] here but just got no response after a couple of attempts, so we just forgot it."

\section{Discussion}

The quality of the relationship between healthcare providers and parents whose child is dying has a significant impact on their experience. Our findings suggest that most parents want these relationships to continue through the dying phase and during their initial bereavement period, though the perceived purpose of the relationship changes. Instead of desiring teamwork and collaboration, parents rely on their relationships to support them as they say goodbye and move into their bereavement journey. The continued presence or absence of these relationships has impacts well beyond the actual hospitalization period of the child, often influencing the parents' entire perception of their child's death.

Our findings suggest that parents continue to need close, ongoing relationships with healthcare providers during and immediately after the time when their child has died. Instead of working as a team to care for the child, these relationships centre around the parents' need 
PARENT-HEALTHCARE PROVIDER RELATIONSHIPS AFTER PICU DEATH

for support and guidance to farewell their child. In line with previous studies of end-of-life care in PICU, we found that ongoing staff support ensures parents have the appropriate privacy and time to say goodbye, and facilitates the creation of mementos (Brooten et al., 2013; Macnab, Northway, Ryall, Scott, \& Straw, 2003; Meert et al., 2009). This is particularly enhanced by the provision of continuity of carer. Parents in our study reported feeling like their child's death was impersonal if too many unknown staff were present. The desire for continuity extended beyond the desire for the same nurse, with many parents asking for the first doctor they developed a relationship with in the PICU to conduct end-oflife discussions and facilitate the withdrawal of life support processes. This is a relatively new finding within the current literature. Currently, appreciation for the importance of continuity of carer, particularly of medical staff, from admission through to death of a child is still relatively absent mentioned by only a limited number of studies (Heller et al., 2005; Meert et al., 2009).

The fact that parents desire involvement in their child's care in PICU, particularly with respect to physical caregiving, is not new and has been identified in many other studies (Richards, Starks, O'Connor, \& Doorenbos, 2017; McGraw et al., 2012; Meert et al., 2009; Meyer et al., 2006; Yorke, 2011). However, currently parental participation in physical care is only explored prior to the child's death and any mention of parental involvement in postmortem care is absent in the PICU end-of-life literature. In contrast, our findings clearly demonstrate that the parental desire to physically care for their child does not stop when the child dies. Instead, many parents in our study had a strong need to participate in post-mortem care as a way to continue their physical caregiving role. For these parents, involvement in post-mortem care was only possible because of the support they received from staff. Without it, many parents would not have felt able to extend their caregiving role into the post-mortem period, demonstrating the value and importance of ongoing staff presence and support for 
PARENT-HEALTHCARE PROVIDER RELATIONSHIPS AFTER PICU DEATH

families in the immediate aftermath of the child's death. We suspect that parents in our study are not unique in this continued desire for involvement in physical caregiving, but rather that the absence of this concept in the literature may be because studies typically focus on the moments of death and then parental experiences of follow up, often overlooking the period of time in hospital after death. Given the significant implications that staff support may have on parents' ability, both physically and psychologically, to care for their child's body, we strongly recommend future research explore parents' perceptions of involvement in postmortem care.

In addition to needing support to say goodbye, parents in our study also desired ongoing close contact with healthcare providers as they attempted to leave the hospital. They frequently wanted a chance to debrief, support to pack their child's belongings, and assistance to leave the PICU and go home. Without it, parents may feel a sense of immediate abandonment, as if staff had simply moved on to other patients. This desire for a 'transition period' between PICU care and home is a new finding; a concept that has not yet been explored within the PICU end of life care literature. Prior studies with bereaved parents in PICU typically do not describe parental feelings of abandonment by healthcare staff until after the parents have left the hospital and follow-up care is not provided (Meert et al, 2009; Meert et al., 2005, Widger \& Picot, 2008). Only one other study has identified this concept, briefly mentioning the devastation parents felt when staff did not support them to leave the hospital (Heller, Solomon, \& Initiative for Pediatric Palliative Care Investigator Team, 2005). In contrast, our findings indicate that maintenance of the parent-healthcare provider relationship for as long as the parents remain in the hospital is extremely important, as it contributes towards the parents' final memories of their child's journey. The impression such ongoing care creates can either be one of support or one of desertion, and, as demonstrated by our findings, is remembered long after the child has died. Given that our findings suggest this 
PARENT-HEALTHCARE PROVIDER RELATIONSHIPS AFTER PICU DEATH

difficult period for parents is often poorly managed, studies exploring the parental needs and perceptions of support as they leave the PICU environment after their child has died are urgently needed.

Consistent with previous studies on parental experiences of child death in PICU (Brink, Thomsen, \& Laerkner, 2017; Butler et al., 2015; Macnab et al., 2003; Meert et al., 2009; Meert et al., 2007; Meert et al., 2005; Yorke, 2011), most parents in our study desired extension of the parent-healthcare provider relationship into the bereavement period. Typically, parents wanted more intensive contact earlier in their bereavement, with support gradually tapered off over a period of approximately 12 months. These timeframes are similar to those mentioned by bereaved parents in prior studies, where follow up contact is recommended within the first 2-4 weeks after death (Macnab et al., 2003) and still desired more than a year later (Yorke, 2011). Though bereaved parents have given some indication as to the length of time support is desired, research on how best to taper and withdraw these supports would be worthwhile, alongside research that explores the longer-term impacts of both having and not having ongoing contact with hospital staff. There is also currently limited research that explores the extent to which bereavement follow up services are provided by PICUs worldwide, or what these services actually provide. We recommend these areas be a focus of future research in order to guide the development of future bereavement follow up programs.

\section{Implications for Practice:}

The findings from our study raise a number of important implications for healthcare providers who are working with children and families at the end of life in the PICU. First and foremost, our findings demonstrate the importance of continuity of carer within the parents' experiences, both during the child's admission and in the hours, days, and months after their death. The importance of continuity of care is reflected within the International Family 
PARENT-HEALTHCARE PROVIDER RELATIONSHIPS AFTER PICU DEATH

Nursing Association (IFNA) guidelines for advanced practice, which state nurses should strive to facilitate continuity of carer within the inter-professional health team (IFNA, 2017). As part of this role, we suggest that nurses act as advocates for the allocation of one or two key 'primary' medical staff and nurses to any child in the PICU, though particularly those who are unlikely to survive, as this may go a long way in enhancing parental perceptions of support.

It is also important to remember that the principles of family centred care do not end when the child has died. In reality, both the principles of family centred care and the IFNA nursing competencies suggest that all members of the child's family are care recipients (IFNA, 2015, 2017; Jolley \& Shields, 2009). The IFNA competencies suggest that nurses form a partnership with the child and family during care delivery (IFNA, 2015). However, nurses must remember that this partnership does not end just because the child has died. Many members of the child's family continue to need care from the healthcare staff immediately after the child's death. We strongly recommend that a nurse or other key staff member remain allocated to care for the family for as long as they remain in hospital. Wherever possible, the allocated staff member should have been present during the child's death, to improve perceptions of support, and should not be expected to care for other patients or undertake other tasks until after the family has gone home.

Our findings also demonstrated how this ongoing partnership between nurses and families enabled parental involvement in post-mortem care. It is important that healthcare providers ensure that every family is offered the opportunity to be involved in post mortem care, no matter the age or physical condition of the child. However, nurses should also make it clear to parents that their involvement is in no way expected, but that they will be supported to provide as much or as little care as they want to or can provide. We hope that in this way, 
PARENT-HEALTHCARE PROVIDER RELATIONSHIPS AFTER PICU DEATH

nurses can continue to enable parents to feel safe and supported to care for their child's body across the entire lifespan if they so choose.

In addition, bereaved parents in this study continued to recommend implementation of bereavement follow-up programs run by the hospital, suggesting that current services are inadequate, either in number or because the services provided do not meet their needs. If ongoing bereavement support from the hospital was not available, parents appreciated referrals or connections to external services able to provide such support. Despite parents wanting referrals to bereavement or counselling services, both our own findings and the limited evidence available would suggest that these occur, at best, infrequently (Egerod, Kaldan, Coombs, \& Mitchell, 2018; Mitchell, Coombs, \& Wetzig, 2017). In the absence of a referral from PICU staff, many of the parents in our study attempted to make contact themselves with bereavement services only once or twice before they gave up. Therefore, in line with the recent INFA guidelines (IFNA, 2015, 2017), we strongly recommend that nurses who work in a PICU without a formal ongoing bereavement follow up program refer and connect to appropriate community based bereavement services, such as SIDS and KIDS in Australia. Healthcare providers should also ensure they are familiar with local bereavement counsellors or organisations in their area so they are able to refer parents appropriately. Ideally, parents would be referred to such services as soon as the child's likely death is recognized, so that some continuity can occur during bereavement follow up. Failing this, appropriate bereavement services should be made aware of newly bereaved PICU families (with the consent of the family), so that they can make contact and remove the burden of seeking follow-up care from the parents themselves. 
PARENT-HEALTHCARE PROVIDER RELATIONSHIPS AFTER PICU DEATH

\section{Limitations}

Though this study is strengthened by the methods inherent to grounded theory, including theoretical sampling and the constant comparative data collection methods, there are limitations. Firstly, most of the parents in this study were Caucasian, with limited prior PICU experience, which may limit transferability of these findings to other families. In addition, though this study was conducted across multiple PICUs, it is possible that the broader Australian culture and healthcare contexts impacted on our findings. Although our study did include a number of children who underwent tissue donation after death, we were unable to recruit any families of children who were brain dead or who participated in organ donation. Our sample also included only one family whose child died from unsuccessful CPR. It is possible that these families have differing follow up needs, and as such, our findings may not completely capture their experiences. In addition, we were unable to recruit families of deceased school aged children; all of the deceased children in our study were infants, toddlers, or teenagers. Though our sample does align with the most common age groups for both admission and mortality within Australian PICUs (ANZPICR, 2016), the lack of data from parents of school aged children may still limit the relevance of our findings to these families.

We also had difficulties with participant recruitment at hospital 3 due to the closure of the hospital immediately prior to our recruitment period, resulting in a loss of bereavement follow-up records and social workers involved in recruitment for our study. Given that this hospital had the most comprehensive bereavement follow-up program of all the included PICUs, it is possible that more participants from this site may have had a significant impact on our data analysis. However, this does not discount the importance of our findings, particularly with respect to the value of follow up care, and the distress caused when it is not offered. There is also the possibility that the prolonged timeframe between the child's death 
PARENT-HEALTHCARE PROVIDER RELATIONSHIPS AFTER PICU DEATH

and our data collection required by the ethics committees in this study led to some degree of recall bias for some of the participants. However, we did not notice any differences in the level of detail recounted by parents whose children died 3-4 years prior to their interview when compared with those whose children died only 1-2 years prior, and do not believe this impact was significant. Finally, participation in this study was voluntary. Though our study included a number of parents who did not want follow up care, it is possible that parents suffering from what may be considered 'complicated grief' may not have taken part, or may not have been approached by social workers.

\section{Conclusion}

The death of a child is one of the most devastating events a parent can endure. When this occurs in the PICU, unfamiliarity with the hospital system may make it even more difficult for parents, who are often unsure how to say goodbye to their child and leave the PICU. Our findings clearly demonstrate that parents rely on the relationships they had developed with their child's healthcare providers in the immediate, not just protracted, aftermath of the child's death. We have shown the importance of maintaining these ongoing relationships whilst the family remains in hospital, both because it enables parents to feel enabled to continue physical caregiving in the post-mortem period, and because it reduces parental feelings of isolation immediately after the child has died. Our findings demonstrate the harm that may be caused if parents feel their relationships with staff are suddenly withdrawn when their child dies, and introduce the possibility of abandonment much earlier in the parents' bereavement journeys than it had previously been acknowledged. Continuation of these relationships into the bereavement period is vital, with bereaved parents needing ongoing, gradually tapered support to adjust to life without their child, or at the very least, referrals to local bereavement services. If these relationships are not maintained, our findings suggest external bereavement services may only have one opportunity to connect with 
PARENT-HEALTHCARE PROVIDER RELATIONSHIPS AFTER PICU DEATH

families; if a supportive response is not offered in the first instance of parents' reaching out, the family is unlikely to try again. In these instances, many grieving families may lack support during one of the most difficult periods of their lives.

\section{Declaration of Conflicting Interests}

The Authors declare that there are no conflicts of interest. 
PARENT-HEALTHCARE PROVIDER RELATIONSHIPS AFTER PICU DEATH

\section{References}

Ames, K., Rennick, J., \& Baillargeon, S. (2011). A qualitative interpretive study exploring parents' perception of the parental role in the paediatric intensive care unit. Intensive and Critical Care Nursing, 27, 143-150. https://doi.org/10.1016/j.iccn.2011.03.004

Australian and New Zealand intensive care registry (ANZPICR). (2016). Report of the Australian and New Zealand Paediatric Intensive Care Registry 2015. Queensland, Australia: Australian and New Zealand Intensive Care Society.

Birks, M., \& Mills, J. (2011). Grounded theory: A practical guide. London, United Kingdom: SAGE Publications

Brink, H. L., Thomsen, A. K., \& Laerkner, E. (2017). Parents' experience of a follow-up meeting after a child's death in the Paediatric Intensive Care Unit. Intensive and Critical Care Nursing, 38, 31-39. https://doi.org/10.1016/j.iccn.2016.06.006

Brooten, D., Youngblut, J. M., Seagrave, L., Caicedo, C., Hawthorne, D., Hidalgo, I., \& Roche, R. (2013). Parent's perceptions of health care providers actions around child ICU death: What helped, what did not. American Journal of Hospice and Palliative Medicine, 30, 40-49. https://doi.org/10.1177/1049909112444301

Burns, J., Sellers, D., Meyer, E., Lewis-Newby, M., \& Truog, R. (2014). Epidemiology of death in the PICU at five US teaching hospitals*. Critical Care Medicine, 42, 21012108. https://doi.org/10.1097/CCM.0000000000000498

Butler, A. E., Copnell, B., \& Hall, H. (2017). Welcoming expertise: Bereaved parents' perceptions of the parent-healthcare provider relationship when a critically ill child is admitted to the paediatric intensive care unit. Australian Critical Care, Epub ahead of print. https://doi.org/10.1016/j.aucc.2017.09.004

Butler, A. E., Copnell, B., \& Hall, H. (2018). "Some were certainly better than others" Bereaved parents' judgements of healthcare providers in the paediatric intensive care 
PARENT-HEALTHCARE PROVIDER RELATIONSHIPS AFTER PICU DEATH

unit: A grounded theory study. Intensive and Critical Care Nursing, 45, 18-24. https://doi.org/10.1016/j.iccn.2017.12.003

Butler, A. E, Hall, H., \& Copnell, B. (2017). Ethical and practical realities of utilising letters for recruitment in bereavement research. Research in Nursing \& Health, 40, 372-377. https://doi.org/10.1002/nur.21800

Butler, A. E., Hall, H., \& Copnell, B. (2018a). The changing nature of the relationships between parents and healthcare providers when a child dies in the paediatric intensive care unit. Journal of Advanced Nursing, 74, 89-99. https://doi.org/10.1111/jan.13401

Butler, A. E., Hall, H., \& Copnell, B. (2018b). Becoming a team: The nature of the parenthealthcare provider relationship when a child is dying in the pediatric intensive care unit. Journal of Pediatric Nursing, In press.

Butler, A. E., Hall, H., Willetts, G., \& Copnell, B. (2015). Family experience and PICU death: A meta-synthesis. Pediatrics, 136, e961-973. https://doi.org10.1542/peds.20151068

Charmaz, K. (2014). Constructing grounded theory ( $2^{\text {nd }}$ ed.). London, United Kingdom: SAGE Publications.

Devictor, D. J., Latour, J. M., \& EURYDICE II study group. (2011). Forgoing life support: How the decision is made in European pediatric intensive care units. Intensive Care Medicine, 37, 1881-1887. https://doi.org/10.1007/s00134-011-2357-3

Egerod, I., Kaldan, G., Coombs, M., \& Mitchell, M. (2018). Family-centered bereavement practices in Danish intensive care units: a cross-sectional national survey. Intensive and Critical Care Nursing, 45, 52-57. https://doi.org/10.1016/j.iccn.2017.10.003

Hall, E. (2005). Being in an alien world: Danish parents' lived experiences when a newborn or small child is critically ill. Scandinavian Journal of Caring Sciences, 19, 179-185. https://doi.org/10.1111/j.1471-6712.2005.00352.x 
PARENT-HEALTHCARE PROVIDER RELATIONSHIPS AFTER PICU DEATH

Heller, K., Solomon, M., \& Initiative for Pediatric Palliative Care Investigator Team. (2005). Continuity of care and caring: What matters to parents of children with lifethreatening conditions. Journal of Pediatric Nursing, 20, 335-346. https://doi.org/10.1016/j.pedn.2005.03.005

International Family Nursing Association (IFNA). (2015). International Family Nursing Association (IFNA) position statement on generalist competencies for family nursing practice. Retrieved from https://internationalfamilynursing.org/2015/07/25/ifnaposition-statement-on-generalist-competencies-for-family-nursing-practice-2/

International Family Nursing Association (IFNA). (2017). IFNA position statement on advanced practice competencies for family nursing. Retrieved from http://internationalfamilynursing.org/2017/05/19/advanced-practice-competencies/

Jolley, J., \& Shields, L. (2009). The evolution of family-centered care. Journal of Pediatric Nursing, 24, 164-170. https://doi.org/10.1016/j.pedn.2008.03.010

Kipper, D., Piva, J., Garcia, P., Einloft, P., Bruno, F., Lago, P., . . Morais, J. (2005). Evolution of the medical practices and modes of death on pediatric intensive care units in southern Brazil. Pediatric Critical Care Medicine, 6, 258-263. https://doi.org/10.1097/01.PCC.0000154958.71041.37

Lamiani, G., Giannini, A., Fossati, I., Prandi, E., \& Vegni, E. (2013). Parental experience of end-of life care in the pediatric intensive care unit. Minerva Anestesiologica, 79, $1334-1343$.

Macnab, A., Northway, T., Ryall, K., Scott, D., \& Straw, G. (2003). Death and bereavement in a paediatric intensive care unit: Parental perceptions of staff support. Paediatrics \& Child Health, 8, 357-362. 
PARENT-HEALTHCARE PROVIDER RELATIONSHIPS AFTER PICU DEATH

McGraw, S., Truog, R., Solomon, M., Cohen-Bearak, A., Sellers, D., \& Meyer, E. (2012). “I was able to still be her mom" Parenting at end of life in the PICU. Pediatric Critical Care Medicine, 13, 350-356. https://doi.org/10.1097/PCC.0b013e31825b5607

Meert, K., Briller, S., Schim, S. \&Thurston, C. (2008). Exploring parents' environmental needs at the time of a child's death in the pediatric intensive care unit. Pediatric Critical Care Medicine, 9, 623-628. https://doi.org/10.1097/PCC.0b013e31818d30d5.

Meert, K., Briller, S., Myers Schim, S., Thurston, C., \& Kabel, A. (2009). Examining the needs of bereaved parents in the pediatric intensive care unit: A qualitative study. Death Studies, 33, 712-740. https://doi.org/10.1080/07481180903070434

Meert, K., Eggly, S., Pollack, M., Anand, K., Zimmerman, J., Carcillo, J., . . Human Development Collaborative Pediatric Critical Care Research, N. (2007). Parents' perspectives regarding a physician-parent conference after their child's death in the Pediatric Intensive Care Unit. The Journal of Pediatrics, 151, 50-55. https://doi.org/10.1016/j.jpeds.2007.01.050

Meert, K., Thurston, C., \& Briller, S. (2005). The spiritual needs of parents at the time of their child's death in the pediatric intensive care unit and during bereavement: A qualitative study. Pediatric Critical Care Medicine, 6, 420-427. https://doi.org/10.1097/01.PCC.0000163679.87749.CA

Meyer, E., Burns, J., Griffith, J., \& Truog, R. (2002). Parental perspectives on end-of-life care in the pediatric intensive care unit. Critical Care Medicine, 30, 226-231.

Meyer, E., Ritholz, M., Burns, J., \& Truog, R. (2006). Improving the quality of end-of-life care in the pediatric intensive care unit: Parents' priorities and recommendations. Pediatrics, 117, 649-657. https://doi.org/10.1542/peds.2005-0144 
PARENT-HEALTHCARE PROVIDER RELATIONSHIPS AFTER PICU DEATH

Michelson, K., Patel, R., Harber-Barker, N., Emanuel, L., \& Frader, J. (2013). End-of-life care decisions in the PICU: Roles professionals play. Pediatric Critical Care Medicine, 14, e-34-44. https://doi.org/10.1097/PCC.0b013e31826e7408

Mitchell, M., Coombs, M., \& Wetzig, K. (2017). The provision of family-centred intensive care bereavement support in Australia and New Zealand: Results of a cross sectional explorative descriptive survey. Australian Critical Care, 30, 139-144. https://doi.org/10.1016/j.aucc.2016.07.005

PICANet. (2017). Paediatric Intensive Care Audit Network Annual Report 2017. Retrieved from http://www.picanet.org.uk/Audit/Annual-Reporting/. Universities of Leeds and Leicester

Richards, C. A., Starks, H., O'Connor, M. R., \& Doorenbos, A. Z. (2017). Elements of family-centered care in the pediatric intensive care unit: An integrative review. Journal of Hospice and Palliative Nursing, 19, 238-246. https://doi.org/10.1097/njh.0000000000000335

Sands, R., Manning, J., Vyas, H., \& Rashid, A. (2009). Characteristics of deaths in paediatric intensive care: A 10-year study. Nursing in Critical Care, 14, 235-240. https://doi.org/10.1111/j.1478-5153.2009.00348.x

Tong, A., Sainsbury, P., \& Craig, J. (2007). Consolidated criteria for reporting qualitative research (COREQ): A 32-item checklist for interviews and focus groups. International Journal for Quality in Health Care, 19, 349-357. https://doi.org/10.1093/intqhe/mzm042

Widger, K., \& Picot, C. (2008). Parents' perceptions of the quality of pediatric and perinatal end-of-life care. Pediatric Nursing, 34, 53-59. Retrieved from http://www.pediatricnursing.net/ 
PARENT-HEALTHCARE PROVIDER RELATIONSHIPS AFTER PICU DEATH

Yorke, D. (2011). Parents' memories of having a child die in the PICU. CONNECT: The World of Critical Care Nursing, 8, 97-102. Retrieved from http://en.connectpublishing.org/ 
PARENT-HEALTHCARE PROVIDER RELATIONSHIPS AFTER PICU DEATH

Table 1. Characteristics of participant families

\begin{tabular}{|c|c|c|c|c|c|c|}
\hline Parent(s)* & $\begin{array}{l}\text { Age of } \\
\text { child }\end{array}$ & Cause of death & $\begin{array}{l}\text { Type of } \\
\text { death }\end{array}$ & $\begin{array}{l}\text { Length of } \\
\text { stay }\end{array}$ & Follow up received & Time since death \\
\hline \multicolumn{7}{|l|}{ Hospital 1} \\
\hline $\begin{array}{l}\text { Evelyn \& } \\
\text { Joshua }\end{array}$ & $<1$ year & Single organ failure & WLST & 9 days & $\begin{array}{l}\text { Nil from hospital. Ongoing } \\
\text { involvement with bereavement } \\
\text { follow up from external services and } \\
\text { personal counselling }\end{array}$ & $1-2$ years \\
\hline Emma & $<1$ year & SIDS & WLST & 2 days & $\begin{array}{l}\text { Nil from hospital. External personal } \\
\text { counselling (limited duration) }\end{array}$ & $1-2$ years \\
\hline Lucy \& Hudson & $1-5$ years & Sepsis & $\begin{array}{l}\text { Unsuccessful } \\
\text { CPR }\end{array}$ & $<24$ hours & $\begin{array}{l}\text { Nil from hospital initially, then } \\
\text { infrequent follow up from medical } \\
\text { staff and social work. Ongoing } \\
\text { involvement with bereavement } \\
\text { follow up from external services and } \\
\text { personal counselling }\end{array}$ & 1 year \\
\hline $\begin{array}{l}\text { Hannah \& } \\
\text { Daniel }\end{array}$ & $\begin{array}{l}>12 \\
\text { years }\end{array}$ & Metabolic condition & WLST & 5 days & $\mathrm{Nil}$ & $<12$ months \\
\hline Zara \& Ryan & $\begin{array}{l}>12 \\
\text { years }\end{array}$ & $\begin{array}{l}\text { Multi-organ } \\
\text { dysfunction }\end{array}$ & WLST & 12 days & $\begin{array}{l}\text { Incidental follow up from hospital } \\
\text { offered x } 1 \text {. Bereavement support } \\
\text { provided by workplace for limited } \\
\text { duration }\end{array}$ & $1-2$ years \\
\hline Eva & $\begin{array}{l}>12 \\
\text { years }\end{array}$ & Anaphylaxis & WLST & 12 days & $\begin{array}{l}\text { Nil from hospital. Single session } \\
\text { counselling from coroner. Attended } \\
\text { organ donation Memorial Day }\end{array}$ & $3-4$ years \\
\hline
\end{tabular}


PARENT-HEALTHCARE PROVIDER RELATIONSHIPS AFTER PICU DEATH

\begin{tabular}{|c|c|c|c|c|c|c|}
\hline Isabelle & $\begin{array}{l}>12 \\
\text { years }\end{array}$ & Cardiac arrest & WLST & 11 days & $\begin{array}{l}\text { Phone calls from social work } \\
\text { (unclear number or length). External } \\
\text { personal counselling. Attended } \\
\text { organ donation Memorial Day }\end{array}$ & $2-3$ years \\
\hline \multicolumn{7}{|l|}{ Hospital 2} \\
\hline Abigail & $<1$ year & Single organ failure & WLST & 8 weeks & $\begin{array}{l}\text { Brief contact from social work } \\
\text { initially. External personal } \\
\text { counselling }\end{array}$ & $1-2$ years \\
\hline Imogen & $1-5$ years & $\begin{array}{l}\text { Multi-organ } \\
\text { dysfunction/sepsis }\end{array}$ & WLST & $\begin{array}{l}\text { Unclear }(2- \\
3 \text { weeks) }\end{array}$ & $\begin{array}{l}\text { Ongoing mailed invitations to } \\
\text { hospital support group, not utilised. } \\
\text { External personal counselling }\end{array}$ & 3-4 years \\
\hline $\begin{array}{l}\text { Piper \& } \\
\text { Edward }\end{array}$ & $\begin{array}{l}>12 \\
\text { years }\end{array}$ & Neurological injury & WLST & 3 weeks & $\begin{array}{l}\text { Extensive follow up from social } \\
\text { worker, ongoing contact as needed }\end{array}$ & $3-4$ years \\
\hline \multicolumn{7}{|l|}{ Hospital 3} \\
\hline Alice & $1-5$ years & Accident & WLST & 5 days & $\begin{array}{l}\text { Ongoing follow up from social } \\
\text { worker at hospital }\end{array}$ & $1-2$ years \\
\hline \multicolumn{7}{|l|}{ Hospital 4} \\
\hline Vicki \& Nate & $<1$ year & SIDS & WLST & 6 days & $\begin{array}{l}\text { Nil personal from hospital, but } \\
\text { attended hospital Memorial Day. } \\
\text { Follow up provided by external } \\
\text { bereavement service and personal } \\
\text { counselling }\end{array}$ & $2-3$ years \\
\hline Layla & $<1$ year & Neurological injury & WLST & Unclear & $\begin{array}{l}\text { Nil personal from hospital. Attended } \\
\text { hospital Memorial Day }\end{array}$ & $<12$ months \\
\hline
\end{tabular}


PARENT-HEALTHCARE PROVIDER RELATIONSHIPS AFTER PICU DEATH

\begin{tabular}{|c|c|c|c|c|c|c|}
\hline $\begin{array}{l}\text { Sarah \& } \\
\text { Connor }\end{array}$ & $<1$ year & SIDS & WLST & 3 days & $\begin{array}{l}\text { Nil personal from hospital. Offered } \\
\text { and refused memorial days. Follow } \\
\text { up provided by external } \\
\text { bereavement service }\end{array}$ & $1-2$ years \\
\hline Zoe \& Charlie & $<1$ year & Single organ failure & WLST & 2 days & $\begin{array}{l}\text { Limited personal support from } \\
\text { social work and medical staff. } \\
\text { Attended single session of hospital } \\
\text { run support group }\end{array}$ & 2-3 years \\
\hline Jessica & $<1$ year & Single organ failure & WLST & $\begin{array}{l}\text { Unclear (1- } \\
2 \text { weeks) }\end{array}$ & $\begin{array}{l}\text { Personal follow up from social work } \\
\text { and medical staff. Attended external } \\
\text { personal counselling }\end{array}$ & 2-3 years \\
\hline Jasmine & $<1$ year & Single organ failure & WLST & 5 days & $\begin{array}{l}\text { Limited personal follow up from } \\
\text { social work. Follow up provided by } \\
\text { external health provider }\end{array}$ & $1-2$ years \\
\hline Erin & $1-5$ years & Single organ failure & WLST & Unclear & $\begin{array}{l}\text { Nil personal. Attended hospital } \\
\text { Memorial Day. Follow up provided } \\
\text { by external bereavement support } \\
\text { service }\end{array}$ & $3-4$ years \\
\hline
\end{tabular}

*pseudonym used

CPR-Cardio-pulmonary resuscitation

SIDS- Sudden Infant Death Syndrome

WLST- Withdrawal of life-supportive therapy 


\begin{tabular}{|c|c|c|c|}
\hline Data & Code & Sub-Category & Phase \\
\hline $\begin{array}{l}\text { "I picked out an outfit that I had in the nappy bag for her, } \\
\text { um.....'cause I bathed her before.... I got to bath her before } \\
\text { we turned the machines off too. And then I got to bath her } \\
\text { afterwards." }\end{array}$ & Caring for my child's body & \multirow{4}{*}{ Saying goodbye } & \multirow{7}{*}{$\begin{array}{c}\text { Gradually } \\
\text { disengaging }\end{array}$} \\
\hline $\begin{array}{l}\text { "They put together like a memory box for us before we left } \\
\text { the hospital ..... I think it was like a little lock of hair, and a } \\
\text { couple of photos......that she'd taken. So that was nice." }\end{array}$ & Creating mementos & & \\
\hline $\begin{array}{l}\text { "We stayed in the same little room thing but they just pulled } \\
\text { all the curtains around and we just sat there. They got like, } \\
\text { they brought a recliner in for me. And sat me down and then } \\
\text { put him on me, and ... um, honestly it was really peaceful." }\end{array}$ & Creating family intimacy & & \\
\hline $\begin{array}{l}\text { "When you hear terrible news you want to be around } \\
\text { someone who at least cares one inch. And when you've got } \\
\text { that bond with a nurse, you have that feeling....this nurse } \\
\text { cares about our family, this nurse cares about our child." }\end{array}$ & Feeling known & & \\
\hline $\begin{array}{l}\text { "The social worker just sort of pointed us in the right } \\
\text { direction. She got us the numbers that we needed, people to } \\
\text { talk to and then the coroner's office." }\end{array}$ & Needing a guide & \multirow{3}{*}{ Going home } & \\
\hline $\begin{array}{l}\text { "It would have been nice to have just had something there } \\
\text { just to bridge that gap a bit, maybe a bit of parent support } \\
\text { there as well." }\end{array}$ & Warming down & & \\
\hline $\begin{array}{l}\text { "I remember just walking out of the PICU unit, just me and } \\
\text { Zoe just by ourselves. So that probably ... you probably just } \\
\text { feel like ... You just feel like what happens now? ..... Maybe to } \\
\text { have someone there or something like that. Whether it is }\end{array}$ & Leaving together & & \\
\hline
\end{tabular}




\begin{tabular}{|c|c|c|c|}
\hline $\begin{array}{l}\text { someone to maybe just even say, 'look we'll just come home } \\
\text { and make sure you get home and everything is okay'." }\end{array}$ & & & \\
\hline $\begin{array}{l}\text { "After she had passed, and they'd taken her...we were sort of } \\
\text { just left there." }\end{array}$ & Feeling abandoned & & \\
\hline $\begin{array}{l}\text { "To know that that nurse, to have even one follow up phone } \\
\text { call from that particular nurse, would have incredible value." }\end{array}$ & $\begin{array}{l}\text { Maintaining a supportive } \\
\text { connection }\end{array}$ & \multirow{6}{*}{ Seeking supports } & \\
\hline $\begin{array}{l}\text { "I got a phone call not long after, like maybe a couple of } \\
\text { weeks, and then I think I might have got another phone call, } \\
\text { like maybe a couple of months after. And then I got sent a } \\
\text { letter from the social worker." }\end{array}$ & Tapering supports & & \\
\hline $\begin{array}{l}\text { "Some of them came to Ruby's funeral. And that was really } \\
\text { meaningful and special." }\end{array}$ & Valuing contact & & \\
\hline $\begin{array}{l}\text { "She gave me that information of who to talk to and where } \\
\text { to go when coming back here" }\end{array}$ & Connecting to services & & \\
\hline $\begin{array}{l}\text { "Once we were out of there, we were gone. Forgotten } \\
\text { about." }\end{array}$ & 'They've forgotten you' & & \\
\hline $\begin{array}{l}\text { "I tried to get into some grievance counselling , but it was a } 6 \\
\text { month...6 week wait. I'm like "Oh nup, I need to talk to } \\
\text { someone now" so I looked up youth....youth services. And I } \\
\text { managed to get just general counselling." }\end{array}$ & Seeking own supports & & \\
\hline
\end{tabular}

